\title{
Changes in feed intake, nutrient digestion, plasma metabolites, and oxidative stress parameters in dairy cows with subacute ruminal acidosis and its regulation with pelleted beet pulp
}

Yongqing Guo ${ }^{\dagger}$, Xiaofeng $\mathrm{Xu}^{\dagger}$, Yang Zou, Zhanshan Yang, Shengli Li ${ }^{*}$ and Zhijun Cao*

\begin{abstract}
The objectives of this study were to 1) determine the variation of nutrient digestion, plasma metabolites and oxidative stress parameters triggered by induced subacute ruminal acidosis (SARA); and 2) evaluate the ability of pelleted beet pulp (BP) as a replacement for ground corn to alleviate SARA. Eight Holstein-Friesian cows were fed four diets during four successive17-day periods: 1) total mixed ration (TMR) containing $0 \%$ finely ground wheat (FGW) (W0); 2) TMR containing 10\% FGW (W10); 3) TMR containing 20\% FGW (W20); and 4) TMR containing 10\% BP as a replacement for $10 \%$ ground corn (BP10). The SARA induction protocol reduced the mean ruminal pH from 6.37 to 5.94, and the minimum ruminal pH decreased from 5.99 to 5.41 from baseline to challenge period. Mean ruminal $\mathrm{pH}$ increased from 5.94 to 6.05 , and minimum daily ruminal $\mathrm{pH}$ increased from 5.41 to 5.63 , when $\mathrm{BP}$ was substituted for corn. The apparent digestibility of nutrients was not affected by the dietary treatments, except that the digestibility of neutral detergent fibre (NDF) and acid detergent fibre (ADF) was reduced in cows fed the W20 diet compared with cows fed the W0 and W10 diets, and cows fed the BP10 diet had higher NDF and ADF digestibility than the cows fed the W20 diet. Cows fed the W20 diet had a lower plasma concentration of $\beta$-hydroxybutyrate (BHBA), non-esterified fatty acids (NEFA), cholesterol, triglyceride, and total antioxidative capacity (TAC), and a higher plasma concentration of glucose, insulin, malonaldehyde (MDA), super oxygen dehydrogenises (SOD), and glutathione peroxidase (GSH-Px) than cows fed the Wo diet. Substitution of BP for corn increased concentrations of plasma BHBA and TAC, but decreased concentrations of plasma MDA. Our results indicate that reduction of fibre digestion; the concomitant increase of plasma glucose and insulin; the decrease of plasma BHBA, NEFA, cholesterol, and triglyceride; and changes of plasma oxidative stress parameters are highly related to SARA induced by W20 diets. These variables may be alternative candidates for SARA diagnosis. We also suggest that the substitution of BP for corn could reduce the risk of SARA, increase fibre digestion, and improve the antioxidant status in dairy cows.
\end{abstract}

Keywords: Beet pulp, Dairy cow, Nutrient digestion, Oxidative status, Plasma metabolites, Subacute ruminal acidosis

\footnotetext{
* Correspondence: lisheng0677@163.com; caozhijun@cau.edu.cn

${ }^{\dagger}$ Equal contributors

State Key Laboratory of Animal Nutrition, College of Animal Science \&

Technology, China Agricultural University, Beijing 100193, China
} 


\section{Introduction}

Subacute ruminal acidosis (SARA) is one of the most common chronic digestive disorders on intensive dairy farms, and is defined as periods of moderately depressed ruminal $\mathrm{pH}$ (the minimum $\mathrm{pH}$ varies between 5.2 and 5.6) [1]. Clinical signs of SARA may include reduced dry matter intake (DMI) and milk fat content, rumenitis, laminitis, and liver abscesses, as well as increased death loss [2]. Excessive feeding of nonfibrous carbohydrates (NFC), a rapid increase in levels of dietary NFC, or insufficient rumen buffering are important causes of this metabolic disorder [3].

Measuring rumen fluid $\mathrm{pH}$ is the only reliable and accurate tool to diagnose SARA [4]. Because of problems in obtaining samples of rumen fluid, diurnal variation of rumen metabolism, and the lack of pathognomonic signs, SARA is especially difficult to diagnose [5]. Accordingly, there is continued interest in finding quick and simple indicators (e.g., plasma metabolites) as potential diagnostic tools of rumen fermentation pattern and function [6]. Cellulolysis has shown to be impaired by pH below 6.0 to 6.2 [7]; therefore, total tract NDF digestibility might be reduced when rumen $\mathrm{pH}$ is lowered. Plasma metabolites were often used to monitor the health and metabolic status of dairy cows, and Ametaj et al. [8] indicated that dairy cows fed diets containing high rapidly fermentable carbohydrates could greatly perturb the patterns of plasma metabolites. However, there is limited information on the role of high-grain induced SARA on diurnal perturbations of plasma metabolites in dairy cows. Moreover, it is widely accepted that oxidative stress is positively related to high grain or high starch diets of ruminant animals [9], and that high-producing dairy cows exposed to a high-starch diet are more susceptible to inadequate antioxidant status [10], resulting in a poorly functioning immune system and increased risk of rumenitis as well as laminitis. Therefore, the oxidative stress index could be a general approach used in ruminant medicine in the future [11].

Several dietary strategies proposed for use in preventing SARA, such as sodium bicarbonate and monensin, have been studied [12,13]. However, neither of these methods has consistently maintained higher rumen $\mathrm{pH}$ values. Sugar beet pulp (BP) contains approximately $40 \%$ neutral detergent fibre (NDF) and is unique in its high content of soluble fibre (especially pectic substances). Soluble fibre fermentation is thought to produce less lactate and propionate than starch fermentation in the rumen, and it does not inhibit cellulose and hemicellulose digestion [14]. Thus, the substitution of corn grain with BP should prevent unfavourable $\mathrm{pH}$ decline in the rumen. The goal of this research was to test the hypothesis that SARA induced by increasing the levels of FGW in the diet is associated with alterations in feed intake, nutrient digestion, ruminal $\mathrm{pH}$, selected plasma metabolites, and oxidative stress parameters. Another objective of this study was to evaluate the ability of pelleted BP as a replacement for ground corn to alleviate SARA in the long term.

\section{Materials and methods}

\section{Experimental design and animal management}

Animal care and procedures were approved and conducted under established standards of the College of Animal Science \& Technology, China Agricultural University.

Eight multiparous Holstein-Friesian cows $(568.5 \pm 34.7 \mathrm{~kg}$ of BW; $164 \pm 15$ DIM; mean \pm SD), four of which were fitted with ruminal cannulas (10 i.d; Bar Diamond, Parma, ID), were fed a series of diets (Table 1) during four successive periods in this experiment: an initial baseline period with $0 \%$ finely ground wheat (FGW, geometric mean particle sizes: $600 \mu \mathrm{m})$ and starch provided as ground corn, a slowly fermented starch diet (W0 treatment, Baseline period); a second period with $10 \% \mathrm{FGW}$, a section of rapidly fermented starch diet (W10 treatment); a third period with $20 \% \mathrm{FGW}$, a diet containing a large amount of rapidly fermented starch (W20 treatment, Challenge period); and a final period in which the W20 diet was amended by replacing 10\% ground corn with $10 \%$ dried, pelleted BP (BP10 treatment). The specific diets were fed sequentially to all eight cows over four $17-\mathrm{d}$ periods (12d adaptation, $5 \mathrm{~d}$ of measuring), because previous reports suggest that SARA was not immediately and easily reversible $[15,16]$, making other experimental designs (e.g., a Latin square) problematic (e.g., carry-over effects).

The four diets (Table 1) were formulated to meet or exceed the NRC [3] guidelines for $600 \mathrm{~kg}$ multiparous Holstein dairy cows producing $27 \mathrm{~kg}$ of milk/d with $4.0 \%$ fat. The diets were fed as a total mixed ration (TMR) (CAU-mixer wagon model JZC-200, Beijing, China), and the forage component of the diet was a mixture of corn silage, chopped alfalfa hay, and Chinese wild rye. The moisture content of corn silage was determined weekly and used to adjust the ration. During each data collection period, the particle size distribution of TMR (Table 2) was determined using a Penn State Particle Separator (PSPS) as described by Lammers et al. [17].

The experiment was conducted at the dairy farm of the State Key Laboratory of Animal Nutrition (Beijing, China). The cows were housed in individual tie-stalls bedded with rubber mattresses, and had free access to drinking water throughout the trial. They were fed twice daily, in equal amounts, at 0700 and 1900 h. The diets were fed ad libitum to allow for at least $5-10 \%$ orts on an as-fed basis. The cows were milked twice daily at 0630 and $1830 \mathrm{~h}$.

\section{Sampling and analytical procedures Nutrient intake and digestibility}

During d13-d17 of each period, the diets and ort samples of individual cows were harvested daily to calculate 
Table 1 Ingredient composition and chemical analyses of experimental diets

\begin{tabular}{|c|c|c|c|c|}
\hline \multirow[b]{2}{*}{ Item } & \multicolumn{4}{|c|}{ Treatment $^{1}$} \\
\hline & wo & W10 & W20 & BP10 \\
\hline \multicolumn{5}{|l|}{ Ingredient/diets, $\%$ of DM } \\
\hline Corn silage & 33.0 & 27.5 & 22.0 & 22.0 \\
\hline Alfalfa hay & 15.0 & 12.5 & 10.0 & 10.0 \\
\hline Chinese wild rye & 12.0 & 10.0 & 8.0 & 8.0 \\
\hline Corn grain & 18.0 & 18.0 & 18.0 & 8.0 \\
\hline Wheat grain & - & 10.0 & 20.0 & 20.0 \\
\hline Soybean meal & 12.6 & 10.6 & 9.6 & 9.6 \\
\hline Cottonseed meal & 3.5 & 3.5 & 3.5 & 3.5 \\
\hline Corn distillers grains & 1.0 & 3.0 & 3.0 & 3.0 \\
\hline Wheat bran & 0.2 & - & 0.9 & 1.0 \\
\hline Pelleted beet pulp & - & - & - & 10.0 \\
\hline Whole cottonseed & 2.0 & 2.0 & 2.0 & 2.0 \\
\hline Mineral-vitamin premix ${ }^{2}$ & 0.50 & 0.50 & 0.50 & 0.50 \\
\hline Dicalcium phosphate & 0.60 & 0.58 & 0.47 & 0.54 \\
\hline Limestone & 0.50 & 0.69 & 0.92 & 0.70 \\
\hline Sodium bicarbonate & 0.50 & 0.50 & 0.50 & 0.50 \\
\hline Magnesium oxide & 0.15 & 0.15 & 0.15 & 0.15 \\
\hline Salt & 0.50 & 0.50 & 0.50 & 0.50 \\
\hline \multicolumn{5}{|c|}{ Chemical composition, \% DM } \\
\hline$C P$ & 15.8 & 16.2 & 16.5 & 16.4 \\
\hline $\mathrm{NE}_{L}, \mathrm{MJ} / \mathrm{kg}^{3}$ & 6.3 & 6.5 & 6.7 & 6.5 \\
\hline $\mathrm{NFC}^{4}$ & 31.9 & 36.0 & 42.2 & 34.8 \\
\hline NDF & 41.2 & 36.2 & 31.2 & 38.0 \\
\hline ADF & 22.6 & 19.9 & 16.1 & 19.8 \\
\hline $\mathrm{fNDF}^{5}$ & 34.4 & 28.6 & 22.9 & 22.9 \\
\hline Starch & 28.5 & 33.0 & 36.6 & 31.0 \\
\hline Ether extract & 3.4 & 3.4 & 3.3 & 3.0 \\
\hline Ash & 7.7 & 8.2 & 6.8 & 7.8 \\
\hline $\mathrm{Ca}$ & 0.77 & 0.77 & 0.77 & 0.77 \\
\hline Total P & 0.42 & 0.42 & 0.42 & 0.42 \\
\hline$F: C^{6}$ & $60: 40$ & $50: 50$ & $40: 60$ & $40: 60$ \\
\hline $\mathrm{NFC/NDF}$ & 0.77 & 0.99 & 1.35 & 0.92 \\
\hline
\end{tabular}

${ }^{1}$ W0 $=$ TMR containing $0 \%$ wheat; W10 $=$ TMR containing $10 \%$ wheat; W20 = TMR containing $20 \%$ wheat; BP10 $=$ TMR containing $20 \%$ wheat plus $10 \%$ pelleted beet pulp; ${ }^{2}$ Contained (/kg of premix; DM basis): 1,000,000 IU vitamin $\mathrm{A} ; 65,000 \mathrm{IU}$ vitamin $\mathrm{D} ; 5,000 \mathrm{IU}$ vitamin $\mathrm{E}_{;} 2,000 \mathrm{mg} \mathrm{Fe} ; 2,550 \mathrm{mg} \mathrm{Mn} ; 5,500 \mathrm{mg}$ $\mathrm{Zn} ; 1,750 \mathrm{mg} \mathrm{Cu} ; 70 \mathrm{mg} \mathrm{l} ; 40 \mathrm{mg} \mathrm{Co} ; 75 \mathrm{mg} \mathrm{Se} ;{ }^{3}$ Calculated using $\mathrm{NE}_{\mathrm{L}}$ values of feedstuffs from NRC (2001); ${ }^{4}$ Nonfibre carbohydrates $=100$ - (NDF\% + CP\% + Ether extract\% + Ash\%); ${ }^{5}$ Forage neutral detergent fibre; ${ }^{6}$ Forage to concentrate ratio.

nutrient intake. Faecal grab samples (300-500 g fresh basis) were collected on 12 occasions: d14 at 0400,0900 , $1400,1900 \mathrm{~h} ; \mathrm{d} 15$ at 0500, 1000, 1500, $2000 \mathrm{~h}$; and d16 at $0600,1100,1700$, and $2200 \mathrm{~h}$. The daily diets, orts, and faecal matter were pooled by dietary treatment and cows, and stored at $-20^{\circ} \mathrm{C}$ until analysis. After the experiment,
Table 2 Particle size distribution of the experimental diets (\% retained, as-fed basis) ${ }^{2}$

\begin{tabular}{lllll}
\hline & \multicolumn{4}{c}{ Treatments $^{\mathbf{1}}$} \\
\cline { 2 - 5 } PSPS sieving & W0 & W10 & W20 & BP10 \\
\hline$>19 \mathrm{~mm}$ & 37.5 & 33.6 & 31.5 & 27.0 \\
8 to $19 \mathrm{~mm}$ & 20.3 & 18.2 & 13.7 & 22.0 \\
1.18 to $8 \mathrm{~mm}$ & 27.8 & 30.7 & 31.1 & 29.6 \\
$<1.18 \mathrm{~mm}$ & 14.3 & 16.9 & 23.2 & 20.6 \\
\hline
\end{tabular}

${ }^{1}$ W0 $=$ TMR containing $0 \%$ wheat, $\mathrm{W} 10=$ TMR containing $10 \%$ wheat, W20 $=$ TMR containing 20\% wheat, BP10 $=$ TMR containing $20 \%$ wheat plus $10 \%$ beet pulp; ${ }^{2}$ Determined using the Penn State Particle Size Separator (PSPS).

all the samples were dried at $65^{\circ} \mathrm{C}$ in a forced-air oven (Model 2000; Experimental Mill, Beijing, China) for $48 \mathrm{~h}$ to a constant weight, ground through a 1-mm screen using a Wiley mill (standard model 4; Arthur H. Thomas Co., Philadelphia, PA), and analysed for dry matter (DM), acid detergent fibre (ADF) (method 973.18; AOAC 1990) [18], and starch [19]. The NDF was measured by the method of Van Soest et al. [20] with heat-stable $\alpha$-amylase (A-3306; Sigma Chemical Co., St. Louis, MO), and the sodium sulfite and ash concentration was corrected for the Ankom 200 fibre Analyzer (Ankom Technology, Fairport, $\mathrm{NY}$ ). The CP was determined by the micro-Kjeldahl method (method 4.2.08; AOAC 1990). Ether extract (method 920.85; AOAC 1990), ash (942.05; AOAC 1990), calcium and phosphorus (method 945.46; AOAC 1990) were also analysed. The chemical composition of the TMR was calculated from the chemical composition of the concentrate mix and the individual forage in the diets. The diets had a similar chemical composition, except for the higher levels of starch and NFC, and the lower levels of NDF in the higher FGW diets.

The acid-insoluble ash (AIA) was used as an intrinsic digestibility marker to estimate nutrient digestibility in the total tract. The AIA in the diets and the faeces were analysed according to Van Keulen and Young [21], using the equation described by Zhong et al. [22] to calculate the apparent digestibility of a nutrient in the gastrointestinal tract. The equation is as follows: $\mathrm{D}=[1-(\mathrm{Ad} \times$ $\mathrm{Nf}) /(\mathrm{Af} \times \mathrm{Nd})] \times 100$, where $\mathrm{Ad}(\mathrm{g} / \mathrm{kg})$ and $\mathrm{Af}(\mathrm{g} / \mathrm{kg})$ represent the AIA in the diet and faeces, respectively, and $\mathrm{Nd}(\mathrm{g} / \mathrm{kg})$ and $\mathrm{Nf}(\mathrm{g} / \mathrm{kg})$ represent the nutrient in the diet and faeces, respectively.

\section{Ruminal pH, plasma metabolites and oxidative stress parameters}

Ruminal samples were collected for $\mathrm{pH}$ analysis. The ruminal fluid $(100 \mathrm{~mL})$ was sampled at 0700 (before the meal), 1000, 1300, 1600, and $1900 \mathrm{~h}$ at $\mathrm{d} 15$ and d16. The samples were collected manually from the anterior dorsal, anterior ventral, medial ventral, posterior dorsal, and posterior ventral locations within the rumen and composited by cow. They were filtered through four layers of cheesecloth. At 
each sampling time, the $\mathrm{pH}$ was measured immediately after collection using a handheld $\mathrm{pH}$ electrode (Model $\mathrm{pH}$ B-4; Shanghai Chemical, Shanghai, China).

On d17 of each experimental period, $10 \mathrm{~mL}$ of blood was collected via tail venipuncture at $0,3,6,9$, and $12 \mathrm{~h}$ after the morning feeding, into vacutainer tubes (Becton Dickinson, Franklin Lakes, NJ) containing sodium heparin anticoagulant. The plasma was collected after centrifugation at $3,000 \times g$ for $10 \mathrm{~min}$, separated into several aliquots, frozen at $-20^{\circ} \mathrm{C}$, and later analyzed for determination of glucose, insulin, non-esterified fatty acids (NEFA), $\beta$-hydroxybutyrate (BHBA), triglycerides, and cholesterol. All plasma-related measurements were analysed in duplicate. The levels of glucose, triglycerides, and cholesterol in plasma were analysed using a clinical auto-Analyzer (Cobas Integra, C701; Hoffmann-La Roche Ltd., Basel, Switzerland). The glucose concentrations were determined using the GOD/PAP test kit (Merit Choice Bioengineering Co., Ltd., Beijing, China). Triglycerides and total cholesterol concentrations were determined following the kit instructions (Shensuo Unf Medical Diagnostic Article Co., Ltd., Shanghai, China), using the enzymatic method. NEFA and BHBA concentrations in plasma were analysed with a Hitachi 7600 automated biochemistry Analyzer (Hitachi Co., Tokyo, Japan). The NEFA concentration was determined using a commercially available kit (Sekisui Medical Co., Ltd., Tokyo, Japan). BHBA dehydrogenase was used for quantifying the plasma concentrations of BHBA using a commercially available kit (Jingyuan Medical Co., Ltd., Shanghai, China). Plasma insulin levels were determined using an insulin radioimmunoassay kit (Beijing North Institute of Biological Technology, Beijing, China) and with a radioimmunoassay system (xh6080; Xian Nuclear Instrument Factory, Xi'an, China) according to the manufacturer's instructions.

The plasma samples collected at 0 and $6 \mathrm{~h}$ after the morning feeding were used to test the levels of total antioxidative capacity (TAC), malonaldehyde (MDA) super oxygen dehydrogenises (SOD), glutathione peroxidase (GSH-Px) with colorimetric assay kits (Nanjing Jiancheng Bioengineering Institute, Jiangsu, China) following the manufacturer's instructions, using a UV visible Recording Spectrophotometer (UV3600, Daojin Corp., Japan). All samples were tested in duplicate. The TAC level was determined by the reaction of phenanthroline and $\mathrm{Fe}^{2+}$ using Spectrophotometer at $520 \mathrm{~nm}$ [23]. The MDA level was measured by the thiobarbituric acid method [24]. The SOD activity was determined by inhibition of nitroblue tetrazolium reduction due to superoxide anion generation by a xanthine-xanthine oxidase system. The GSH-Px level was determined by using a direct measurement of the remaining GSH after the enzyme-catalysed reaction as described by Hafeman et al. [25].

\section{Statistical analysis}

Data on feed intake and digestibility were analysed using the Proc Mixed SAS procedure (SAS Institute, 2002) using the following model: $Y_{i j}=\mu+T_{i}+C_{j}+\varepsilon_{i j}$, where $\mathrm{Y}_{\mathrm{ij}}=$ the dependent variable, $\mu=$ the overall mean, $\mathrm{T}_{\mathrm{i}}=$ the fixed effect of treatment group, $C_{j}=$ the random animal effect, and $\varepsilon_{\mathrm{ij}}=$ the residual error term.

Measurements of ruminal $\mathrm{pH}$, plasma metabolites and oxidative stress parameters were analysed as repeated measures using Proc Mixed SAS procedure (SAS Institute, 2002) using the following model: $Y_{i j k}=\mu+T_{i}+C_{j}+H_{k}+$ $\mathrm{HT}_{\mathrm{ik}}+\varepsilon_{\mathrm{ijk}}$, where $\mathrm{Y}_{\mathrm{ijk}}=$ the dependent variable; $\mu=$ the overall mean; $T_{i}=$ the effect of treatment $i ; C_{j}=$ the effect of cow j; $\mathrm{H}_{\mathrm{k}}=$ the effect of hours post-feeding analysed as repeated measures; $\mathrm{HT}_{\mathrm{ik}}=$ the interactions between hour $\mathrm{k}$ and treatment $\mathrm{i}$, and $\varepsilon_{\mathrm{ijk}}=$ the random residual error. All the above data were compared with Tukey's range test. Treatment effects were declared significant at $P \leq 0.05$, and tendencies from $P>0.05$ to $\leq 0.10$. The $P$-values indicated in Tables 2, 3, and 4 refer to the overall diet effects.

\section{Results}

\section{Nutrient intake and digestibility}

Total DM and ether extract intake were not significantly affected by dietary treatments (Table 3); however, cows fed the W20 diet had a lower NDF and ADF intake $(P<0.01)$, and a higher $\mathrm{CP}$ and starch intake $(P<0.01)$ than the cows fed the W0 diet. The substitution of BP for ground corn increased NDF and ADF intake $(P<0.01)$, and

Table 3 Effect of dietary treatments on nutrient intake and digestibility in dairy cows ${ }^{1,2}$

\begin{tabular}{|c|c|c|c|c|c|c|}
\hline \multirow[b]{2}{*}{ Item } & \multicolumn{4}{|c|}{ Dietary treatment $^{1}$} & \multirow[b]{2}{*}{$\mathrm{SEM}^{3}$} & \multirow[b]{2}{*}{$P$-value } \\
\hline & wo & W10 & W20 & BP10 & & \\
\hline \multicolumn{7}{|c|}{ Feed intake, kg/d } \\
\hline DM & 18.87 & 19.39 & 19.60 & 19.40 & 0.19 & 0.39 \\
\hline NDF & $7.44^{\mathrm{a}}$ & $6.66^{\mathrm{b}}$ & $5.77^{c}$ & $7.06^{\mathrm{ab}}$ & 0.14 & $<0.01$ \\
\hline ADF & $4.04^{\mathrm{a}}$ & $3.64^{\mathrm{b}}$ & $2.93^{c}$ & $3.65^{\mathrm{b}}$ & 0.09 & $<0.01$ \\
\hline$C P$ & $3.10^{\mathrm{b}}$ & $3.25^{\mathrm{ab}}$ & $3.33^{\mathrm{a}}$ & $3.31^{\mathrm{a}}$ & 0.03 & $<0.01$ \\
\hline Ether extract & 0.63 & 0.65 & 0.63 & 0.66 & 0.01 & 0.07 \\
\hline Starch & $5.50^{c}$ & $6.66^{\mathrm{b}}$ & $7.42^{\mathrm{a}}$ & $6.29^{b}$ & 0.13 & $<0.01$ \\
\hline
\end{tabular}

Apparent digestibility of nutrients, $\%$

$\begin{array}{lllllll}\text { DM } & 72.90 & 70.54 & 72.47 & 70.19 & 0.62 & 0.34 \\ \text { NDF } & 65.96^{\mathrm{a}} & 57.04^{\mathrm{bc}} & 52.33^{\mathrm{c}} & 61.82^{\mathrm{ab}} & 1.36 & <0.01 \\ \text { ADF } & 63.67^{\mathrm{a}} & 55.63^{\mathrm{a}} & 45.57^{\mathrm{b}} & 56.72^{\mathrm{a}} & 1.58 & <0.01 \\ \text { CP } & 75.38 & 72.72 & 75.39 & 71.94 & 0.62 & 0.14 \\ \text { Ether extract } & 70.74 & 63.04 & 65.22 & 65.90 & 1.30 & 0.14 \\ \text { Starch } & 89.38 & 89.29 & 89.93 & 89.35 & 0.27 & 0.84\end{array}$

${ }^{1} \mathrm{~W} 0=$ TMR containing $0 \%$ wheat; $\mathrm{W} 10=$ TMR containing $10 \%$ wheat; $\mathrm{W} 20=$ TMR containing $20 \%$ wheat; BP10 = TMR containing $20 \%$ wheat plus $10 \%$ beet pulp; ${ }^{2} \mathrm{a}-\mathrm{c}$ Means with different superscripts in the same row differ (Tukey's test; $P<0.05) ;{ }^{3} \mathrm{SEM}=$ Standard error of the mean. 
Table 4 Effect of dietary treatments on ruminal $\mathrm{pH}$ and plasma metabolite profiles in dairy cows $^{2,3}$

\begin{tabular}{|c|c|c|c|c|c|c|c|c|}
\hline \multirow[b]{2}{*}{ Item } & \multicolumn{4}{|c|}{ Dietary treatment ${ }^{1}$} & \multirow[b]{2}{*}{$\mathrm{SEM}^{4}$} & \multicolumn{3}{|c|}{$P$-value } \\
\hline & wo & W10 & W20 & BP10 & & Trt & Time & Trt $\times$ Time \\
\hline \multicolumn{9}{|l|}{ Ruminal } \\
\hline $\mathrm{pH}$, Average & $6.37^{\mathrm{a}}$ & $6.01^{b}$ & $5.94^{b}$ & $6.05^{b}$ & 0.05 & $<0.01$ & $<0.01$ & 0.01 \\
\hline pH, Minimum & $5.99^{\mathrm{a}}$ & $5.63^{b}$ & $5.41^{c}$ & $5.63^{b}$ & 0.07 & $<0.01$ & - & - \\
\hline \multicolumn{9}{|l|}{ Plasma } \\
\hline $\mathrm{BHBA}^{5}, \mathrm{mmol} / \mathrm{L}$ & $0.82^{\mathrm{a}}$ & $0.76^{\mathrm{ab}}$ & $0.68^{b}$ & $0.84^{\mathrm{a}}$ & 0.02 & $<0.01$ & $<0.01$ & 0.88 \\
\hline$N E F A^{6}, u E q / L$ & $136.88^{\mathrm{a}}$ & $123.20^{\mathrm{ab}}$ & $115.23^{\mathrm{b}}$ & $111.83^{b}$ & 3.37 & 0.01 & $<0.01$ & 0.58 \\
\hline Cholesterol, mmol/L & $3.71^{\mathrm{a}}$ & $2.97^{\mathrm{b}}$ & $2.41^{c}$ & $2.55^{\mathrm{c}}$ & 0.06 & $<0.01$ & 0.13 & 0.90 \\
\hline Triglyceride, mmol/L & $0.20^{\mathrm{a}}$ & $0.18^{b}$ & $0.17^{c}$ & $0.17^{b c}$ & 0.01 & $<0.01$ & $<0.01$ & 0.98 \\
\hline Glucose, mmol/L & $3.10^{b}$ & $3.13^{b}$ & $3.22^{\mathrm{a}}$ & $3.17^{\mathrm{ab}}$ & 0.01 & $<0.01$ & $<0.01$ & 0.97 \\
\hline Insulin, ulU/mL & $6.19^{b}$ & $7.33^{\mathrm{ab}}$ & $8.00^{\mathrm{a}}$ & $7.62^{\mathrm{a}}$ & 0.22 & $<0.01$ & $<0.01$ & 0.94 \\
\hline
\end{tabular}

${ }^{1}$ W0 = TMR containing $0 \%$ wheat; W10 = TMR containing 10\% wheat; W20 = TMR containing 20\% wheat; BP10 = TMR containing $20 \%$ wheat plus $10 \%$ beet pulp; ${ }^{2} \mathrm{a}-\mathrm{c}$ Means with different superscripts in the same row differ (Tukey's test; $P<0.05$ ); ${ }^{3}$ Blood samples were taken at $0,3,6,9$, and $12 \mathrm{~h}$ post morning feeding; ${ }^{4} \mathrm{SEM}=$ Standard error of the mean; ${ }^{5} \beta$-hydroxybutyrate; ${ }^{6}$ Non esterified fatty acids.

decreased starch intake $(P<0.01)$. Apparent digestibility of $\mathrm{DM}, \mathrm{CP}$, ether extract, and starch was not affected by dietary treatments. However, apparent digestibility of NDF and ADF was lower $(P<0.01)$ for cows fed the W20 diet than for cows fed the W0 diet, and cows fed the BP10 diet had a higher $(P<0.01) \mathrm{NDF}$ and ADF digestibility than the cows fed the W20 diet.

\section{Ruminal pH, plasma metabolites and oxidative stress parameters}

Ruminal $\mathrm{pH}$ profiles on $\mathrm{d} 15$ and $\mathrm{d} 16$ are illustrated in Table 4 and Figure 1. This SARA induction protocol reduced mean ruminal $\mathrm{pH}$ from 6.37 during the baseline period to 5.94 during the challenge period $(P<0.01)$; the minimum ruminal $\mathrm{pH}$ decreased from baseline to challenge period (5.99 vs. 5.41). Based on the definition of SARA as daily episodes of low rumen $\mathrm{pH}$ between 5.2 and 5.6 for at least $180 \mathrm{~min} / \mathrm{d}$ [1], the most severe rumen $\mathrm{pH}$ depression

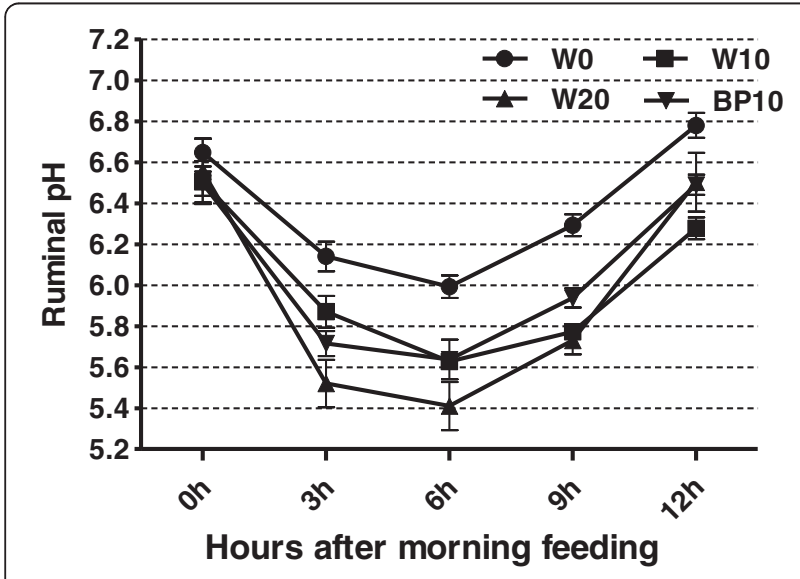

Figure 1 Effect of dietary treatments on diurnal patterns of ruminal $\mathrm{pH}$ in dairy cows. Data are expressed as mean $\pm \mathrm{SE}$. was obtained from cows fed the W20 diet. Ruminal pH from 3 to $9 \mathrm{~h}$ after morning feeding was significantly lower $(P<0.01)$ for cows fed the W20 diet than for cows fed the other diets. Cows fed the BP10 diet had a higher daily mean ruminal $\mathrm{pH}$ (6.05 vs. 5.94) and minimum ruminal $\mathrm{pH}(5.63$ vs. 5.41) than the cows fed the W20 diet. The effects of time and the treatment $x$ time interaction on average ruminal $\mathrm{pH}$ were significant $(P<0.01$ and $P=0.01$, respectively).

Data on diurnal changes of plasma metabolite parameters and oxidative stress parameters are given in Tables 4 and 5 , and Figure 2. Compared with the cows fed the W0 diet, cows fed the W20 diet had a lower concentrations of the plasma BHBA $(P<0.01)$, NEFA $(P=0.01)$, cholesterol $(P<0.01)$, triglyceride $(P<0.01)$, and TAC $(P<0.01)$, and higher concentrations of plasma glucose $(P<0.01)$, insulin $(P<0.01)$, MDA $(P<0.01)$, SOD $(P<0.01)$, and GSH-Px $(P=0.02)$. The substitution of $\mathrm{BP}$ for ground corn increased $(P<0.01)$ plasma concentrations of BHBA and TAC, but decreased $(P<0.01)$ plasma concentration of MDA. Time after morning feeding had an effect $(P<0.01)$ on all plasma metabolite profiles, except the concentration of plasma cholesterol. There was no effect of the treatmentxtime interaction with respect to all plasma metabolite profiles. The effects of time and the treatmentxtime interactionon plasma TAC were significant $(P<0.01)$. There were no effects of time and the treatmentxtime interaction with respect to plasma concentrations of MDA, SOD, and GSH-Px, except the concentration of plasma MDA was affected by the treatment $\times$ time interaction $(P<0.01)$.

\section{Discussion}

\section{Nutrient intake and digestibility}

The findings of this study concur with the results of others [4,26]; DMI was not different between the dietary treatments. Paradoxically, reduced DMI was seen as a 
Table 5 Effect of dietary treatments on oxidative stress parameters in dairy cows ${ }^{2,3}$

\begin{tabular}{|c|c|c|c|c|c|c|c|c|}
\hline \multirow[b]{2}{*}{ Item } & \multicolumn{4}{|c|}{ Dietary treatment ${ }^{1}$} & \multirow[b]{2}{*}{$\mathrm{SEM}^{4}$} & \multicolumn{3}{|c|}{$P$-value } \\
\hline & wo & W10 & W20 & BP10 & & $\overline{T r t}$ & Time & Trt $\times$ Time \\
\hline $\mathrm{TAC}^{5}, \mathrm{U} / \mathrm{mL}$ & $6.14^{\mathrm{a}}$ & $6.37^{\mathrm{a}}$ & $5.30^{\mathrm{b}}$ & $5.94^{\mathrm{a}}$ & 0.10 & $<0.01$ & $<0.01$ & $<0.01$ \\
\hline $\mathrm{MDA}^{6}, \mathrm{nmol} / \mathrm{mL}$ & $3.11^{\mathrm{c}}$ & $3.14^{c}$ & $4.39^{\mathrm{a}}$ & $3.56^{\mathrm{b}}$ & 0.08 & $<0.01$ & 0.21 & $<0.01$ \\
\hline $\mathrm{SOD}^{7}, \mathrm{U} / \mathrm{mL}$ & $65.21^{c}$ & $67.63^{\mathrm{bc}}$ & $73.34^{\mathrm{a}}$ & $70.88^{\mathrm{ab}}$ & 0.96 & $<0.01$ & 0.70 & 0.07 \\
\hline GSH-Px' ${ }^{8}, \mathrm{U} / \mathrm{mL}$ & $36.37^{b}$ & $41.48^{\mathrm{ab}}$ & $43.34^{\mathrm{a}}$ & $41.21^{\mathrm{ab}}$ & 0.99 & 0.02 & 0.06 & 0.07 \\
\hline
\end{tabular}

${ }^{1}$ W0 = TMR containing $0 \%$ wheat; W10 = TMR containing $10 \%$ wheat; W20 = TMR containing $20 \%$ wheat; BP10 = TMR containing $20 \%$ wheat plus $10 \%$ beet pulp; ${ }^{2} \mathrm{a}-\mathrm{c}$ Means with different superscripts in the same row differ (Tukey's test; $P<0.05$ ); ${ }^{3}$ Blood samples were taken at 0 and $6 \mathrm{~h}$ post morning feeding; ${ }^{4} \mathrm{SEM}=$ Standard error of the mean; ${ }^{5}$ Total antioxidative capacity; ${ }^{6}$ Malonaldehyde; ${ }^{7}$ Super oxygen dehydrogenises; ${ }^{8} \mathrm{Glutathione}$ peroxidase.

clinical sign of SARA [27], and several researchers have shown that DMI decreased during induced SARA experiments $[28,29]$. The effects of induced SARA on DMI were inconsistent, and the causes of this are unclear, probably because of the variance of SARA induction protocol, the severity of SARA, or the individual difference of the cows. Moreover, higher intake and high concentrate included in the W20 diet may have confounded the results. The variation in intakes of $\mathrm{CP}, \mathrm{NDF}, \mathrm{ADF}$, and starch with changes in the ratio of forage to concentrate $(\mathrm{F}: \mathrm{C})$ reflected the chemical composition of the diet consumed because DMI was not affected by F:C.

Here, total tract digestibility of NDF and ADF were reduced in cows fed the W20 diet, although the NDF and $\mathrm{ADF}$ intakes were lower than those fed the other diets. This result may be reflected by higher ruminal fermentation of wheat starch of the W20 diet, as well as the negative-associated effects of fibre degradability in the rumen with dietary fermentable carbohydrates [30,31]. Excessively low ruminal $\mathrm{pH}$ values can be a problem in dairy cows receiving a diet with large amounts of concentrate or fermentable starch when volatile fatty acid (VFA) production exceeds the buffering ability of the rumen contents. Moreover, fibre digestion can be reduced at $\mathrm{pH} 6$ or less in the rumen [6]. An in vitro study by Stensig et al. [32] showed that with the higher levels of dietary fermentable starch (wheat), NDF digestion and passage rate were reduced. During the control periods and SARA periods, the 24- and 48-h in situ NDF degradabilities of corn silage were reduced from 44.0 to $37.2 \%$ and from 56.1 to $44.8 \%$, respectively [33]. The total tract digestibility of NDF and ADF increased in cows fed the BP10 diet compared with cows fed the W20 diet, and the results might be due to the higher ruminal $\mathrm{pH}$ of cows fed the diet inclusion of BP. Our results were consistent with a previous study, which showed that substitution of BP for barley grain in a lowforage diet exhibited a higher apparent digestibility of NDF in dairy cows [34].Wheat grain exhibits faster and more extensive starch and CP degradation in the rumen [35], and it was expected that total tract starch digestibility would be greater in cows fed the higher FGW diets; however, total tract digestibility of $\mathrm{CP}$ and starch were not different among treatments. This was unexpected and is difficult to explain.

\section{Ruminal $\mathrm{pH}$ and plasma metabolites}

Low ruminal $\mathrm{pH}$ was observed in cows fed the W20 diet; the minimum ruminal $\mathrm{pH}$ was around 5.4, which was consistent with SARA [1]. SARA induced by increasing the levels of starch and reducing the F:C ratio of the diet results in the accumulation of organic acids (mainly short-chain VFA) in the rumen, as well as reduction in chewing capacity and rumination activity. This in turn leads to an increase in rumen acidity and a decrease in rumen buffering capacity [2]. Increasing ruminal $\mathrm{pH}$ with the inclusion of BP in the diet was attributed to the lower production of lactate and propionate from pectic substances in the rumen than the inclusion of corn in the diet [14]. Moreover, compared with the W20 diet, the BP10 diet could increase the levels of NDF and peNDF in dietary DM in our study, and then would increase chewing time and salivary secretion.

The concentrations of plasma BHBA, cholesterol and triglyceride were lower in cows fed the W20 diet throughout the daytime, and the results reveal that SARA had a significant effect on diurnal fluctuations in plasma metabolites. Similarly, a previous study showed that dairy cows fed increasing levels of barley grain were associated with lower concentrations of plasma BHBA and cholesterol [8]. Plasma BHBA comes from the NEFA oxidation in hepatic tissue [36] or from absorbed butyrate [37]. The lower concentration of plasma BHBA is probably due to the variation of its sources and the higher energy density of the W20 diet than that of the other diets. The diurnal fluctuations of plasma BHBA showed the reverse trend compared with those of plasma NEFA in our study, and this is partly explained by the fact that plasma BHBA is produced in the liver and in the rumen epithelium [38]. That is, the higher plasma NEFA concentration in the morning hours could enhance the production of BHBA from NEFA in hepatic tissue, so as to compensate for the relatively low production of BHBA by rumen epithelial cells. The substitution of $\mathrm{BP}$ for ground corn increased the concentration of 


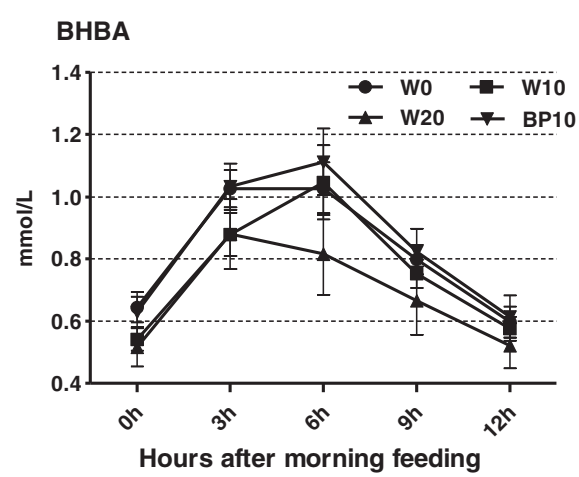

Cholesterol
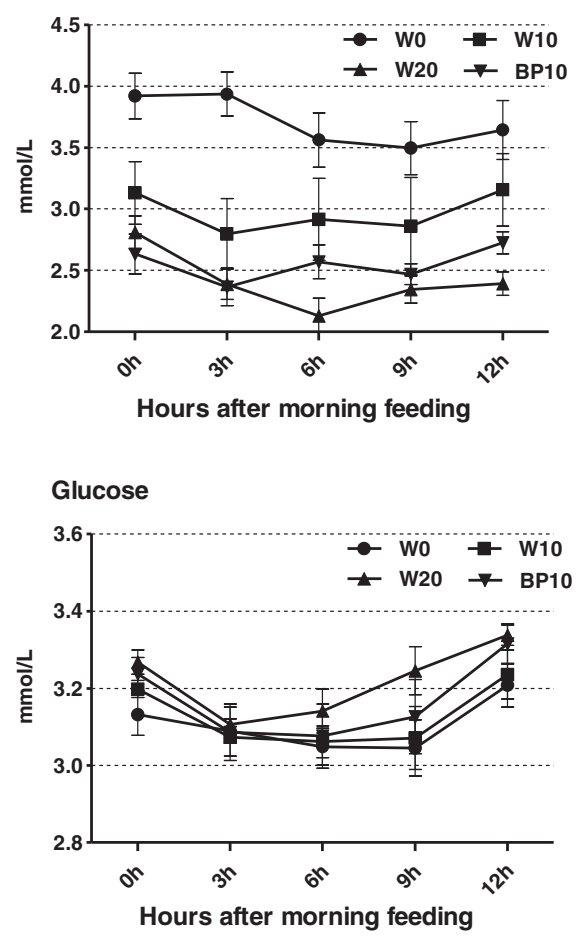

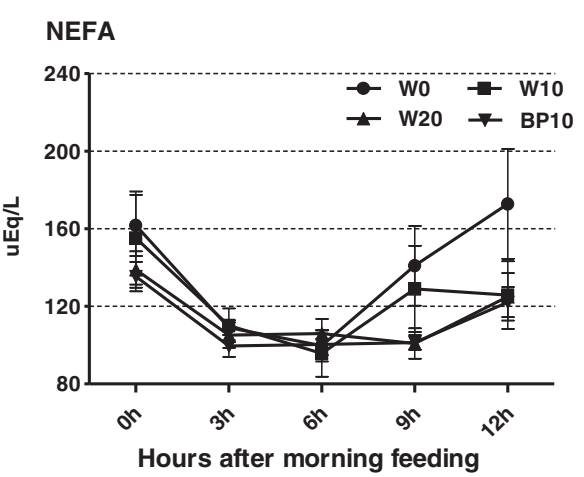

Triglyceride
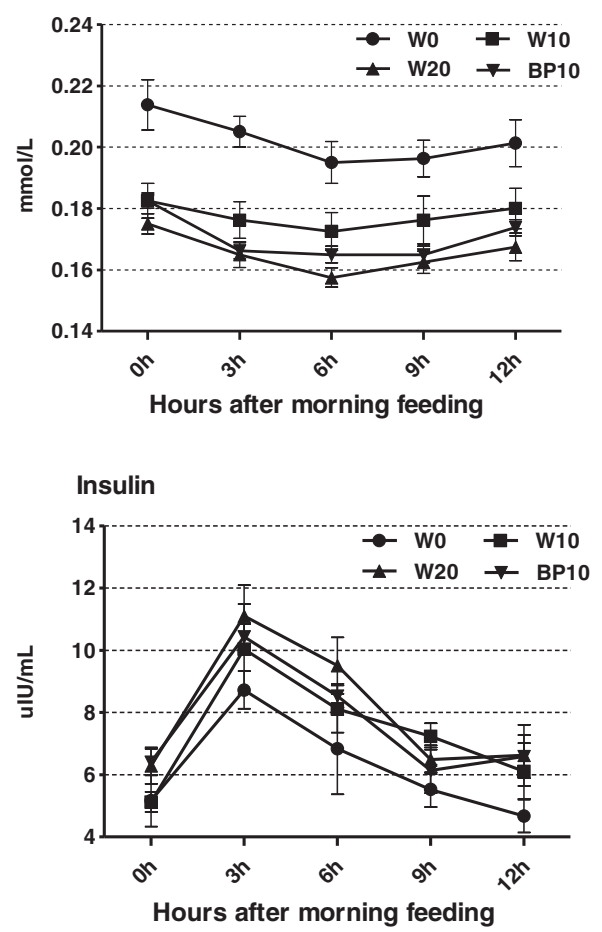

Figure 2 Effect of dietary treatments on diurnal patterns of plasma metabolites in dairy cows. Data are expressed as mean \pm SE.

plasma BHBA (mean BHBA concentrations were within the normal range), probably because of the variation of $\mathrm{pH}$ value and the fermentation acid concentration in the rumen between the two diets.

Low plasma cholesterol is associated with disturbances of plasma amino acids and severity of the acute phase response [39]. Previous researchers have demonstrated that dairy cows fed large amounts of concentrate or grain-induced SARA often show changes in the composition of rumen microbiota and a rapid accumulation of large amounts of bacterial endotoxin (or lipopolysaccharide, LPS) in the rumen $[28,40]$. The inverse relationships were found between the concentration of rumen endotoxin and the concentration of plasma cholesterol [6], and low plasma cholesterol levels in cows fed the
W20 diets could be related to the systemic inflammatory response triggered by release of endotoxin into the peripheral circulation [28]. Lower plasma triglyceride concentrations were found in cows fed the W20 diet. This is probably due to decreased lipolysis and ruminal biohydrogenation of dietary unsaturated FA at low ruminal $\mathrm{pH}$ [41] or higher energy density of the W20 diet, thereby reducing saturated NEFA from the rumen and triglyceride levels in peripheral blood circulation.

The plasma NEFA level has always been used as an indicator of energy status in dairy cows [42]. Cows fed the W20 diet had reduced concentrations of plasma NEFA compared with the other three diets. This finding was similar to the observations of Ametaj et al. [8], who demonstrated that the levels of plasma NEFA were lower in cows 
fed high-grain (barely) diets. The release of NEFA in plasma is based on their mobilization from the adipose triacylglycerol (TG) stores through the process of lipolysis. Increasing the proportion of FGW in the diet could potentially improve the energy balance of dairy cows. Moreover, the abundant availability of ruminal propionate (data not shown) and a higher plasma insulin concentration in our study might have contributed to the reduced concentration of plasma NEFA due to a propionate and insulin inhibitory effect on the NEFA release by adipose tissue [43].

Data from this research showed that cows fed the W20 diet had the greatest concentrations of plasma glucose and insulin. This result can be explained by the enhanced production of ruminal propionate as well as the conversion to the end product in the liver through the process of hepatic glucogenesis [44]. This finding is in accordance with a previous report from Ametaj et al. [8], who suggested that feeding diets containing large amounts of fermentable carbohydrates is related to a greater concentration of plasma glucose in dairy cows. Ruminal propionate and plasma glucose are secretagogues for pancreatic release of insulin, and insulin is reported to inhibit hepatic gluconeogenesis [45]. Thus, the increased plasma insulin concentration in cows fed the W20 diet, in the present study, is due to high concentration of ruminal propionate and plasma glucose associated with high FGW induced SARA.

\section{Oxidative stress parameters}

Oxidative stress is a contributory factor to increase the susceptibility of the disease in dairy cows [46]. Lipid peroxidation (MDA) in plasma is one of the important consequences of oxidative stress, and it can be used as a reliable marker for the evaluation of the severity of oxidative stress [47]. TAC is an integrated parameter that aims to describe the dynamic equilibrium between prooxidants and antioxidants in the plasma compartment [48]. Here, cows fed the W20 diet had increased concentrations of MDA, and reduced levels of TAC. It is suggested that cows fed a high fermentable carbohydrate diet were more susceptible to oxidative stress than the other dietary treatments. The results were similar to a report from Hou et al. [49], who demonstrated that cows fed high grain diets had a lower content of serum TAC, and higher contents of serum MDA; the homeostasis of rumen and oxidative stress of the body were significantly affected by dietary F:C. Gabai et al. [50] reported that high-starch diets lead to an increase in oxidative stress of early lactation dairy cows, which could be caused by changes in oxidative phosphorylation. Taking into account the plasma metabolic changes (e.g., BHBA, cholesterol, and NEFA) mentioned above, the contents of MDA and TAC in plasma could be considered a reflection of the homeorhetic balance that occurs during SARA.
Moreover, diets rich in readily available carbohydrates adversely affect rumen metabolism, which is associated with an increase in the yield of harmful and toxic substances (e.g., lactate, ethanol, histamine, tyramine, and endotoxin) in the rumen [51], and potentially causes systemic immune suppression and metabolic changes in dairy cows [1]. Therefore, there is a large possibility that oxidative stress plays a major role in the inflammation and immune dysfunction that occurs after induced SARA in dairy cows. The higher concentration of plasma TAC and lower concentration of plasma MDA in the cows fed the BP10 diet than the cows fed the W20 diet could be related to the higher ruminal $\mathrm{pH}$ than the induced SARA, and thus would decrease the negative effects of a more intensive fermentation of easily fermentable carbohydrates in the rumen.

SOD is involved in the conversion of oxygen radicals to peroxides, and GSH-Px is involved in removing the peroxides produced by SOD enzyme and converting them into water [52]. Here, a higher concentration of plasma MDA and lower concentration of plasma TAC in cows fed the W20 diet resulted in greater SOD and GSH-Px activity in plasma. It might be necessary for both enzymes to be active for adequate removal of end products of lipid peroxidation (e.g., MDA), to alleviate some of the toxic effects of reactive oxygen species (ROS), and to increase the antioxidant status of the animal [53]. A negative relationship between the activity of plasma SOD and GSH-Px and the production of plasma MDA in early lactation dairy cows was also found by Sharma et al. [54].

\section{Conclusions}

SARA induced by high FGW diets resulted in strong modifications of fibre digestion, plasma metabolites, and oxidative status of dairy cows. The reduction of fibre digestion, the alterations of concentrations of selected metabolites related to carbohydrate and lipid metabolism (e.g., cholesterol, BHBA, NEFA, and triglyceride), and the changes of oxidative stress parameters (e.g., MDA, TAC, and SOD) in the plasma, are alternative candidates for diagnosis of SARA in cows of the same physiological state and environment. Substitution of pelleted BP for ground corn could reduce the risk of SARA, increase fibre digestion, and improve antioxidant status in dairy cows.

\section{Competing interests}

The authors declare that they have no competing interests.

\section{Authors' contributions}

$Y G, X X, Y Z$, and $Z Y$ carried out the experiments. SL and ZC participated in the design of the study, performed the statistical analysis, and drafted the manuscript. All authors read and approved the final manuscript.

\section{Acknowledgment}

This experiment was financially supported by funds from the National Key Basic Research Program of China (Project No. 2011CB100801). 
Received: 19 March 2013 Accepted: 13 August 2013

Published: 16 August 2013

\section{References}

1. Gozho GN, Plaizier JC, Krause DO, Kennedy AD, Wittenberg KM: Subacute ruminal acidosis induces ruminal lipopolysaccharide endotoxin release and triggers an inflammatory response. J Dairy Sci 2005, 88:1399-1403.

2. Plaizier JC, Krause DO, Gozho GN, McBride BW: Subacute ruminal acidosis in dairy cows: the physiological causes, incidence and consequences. Vet J 2008, 176:21-31.

3. National Research Council (NRC): Nutrient requirements of dairy cattle. 7th edition. Washington, DC: National Academy Press; 2001

4. Keunen JE, Plaizier JC, Kyriazakis L, Duffield TF, Widowski TM, Lindinger MI, McBride BW: Effects of a subacute ruminal acidosis model on the diet selection of dairy cows. J Dairy Sci 2002, 85:3304-3313.

5. Gianesella M, Morgante M, Stelletta C, Ravarotto L, Giudice E, Van Saun RJ: Evaluating the effects of rumenocentesis on health and performance in dairy cows. Acta Vet Brno 2010, 79:459-468.

6. Zebeli Q, Dunn SM, Ametaj BN: Perturbations of plasma metabolites correlated with the rise of rumen endotoxin in dairy cows fed diets rich in easily degradable carbohydrates. J Dairy Sci 2011, 94:2374-2382.

7. Mould FL, Ørskov ER: Manipulation of rumen fluid pH and its influence on cellulolysis in Sacco, dry matter degradation and the rumen microflora of sheep offered either hay or concentrate. Anim Feed Sci Tech 1983, 10:1-14.

8. Ametaj BN, Emmanuel DG, Zebeli Q, Dunn SM: Feeding high proportions of barley grain in a total mixed ration perturbs diurnal patterns of plasma metabolites in lactating dairy cows. J Dairy Sci 2009, 92:1084-1091.

9. Sgorlon S, Stradaioli G, Gabai G, Stefanon B: Variation of starch and fat in the diet affects metabolic status and oxidative stress in ewes. Small Ruminant Res 2008, 74:123-129.

10. Lohrke B, Viergutz T, Kanitz W, Gollnitz K, Becker F, Hurtienne A, Schweigert FJ: High milk yield in dairy cows associated with oxidant stress. Online Vet Res 2004, 8:70-78.

11. Celi P: Biomarkers of oxidative stress in ruminant medicine. Immunopharm Immunot 2011, 33:233-240.

12. Paton $L$, Beauchemin KA, Veira DM, von Keyserlingk MAG: Use of sodium bicarbonate, offered free choice or blended into the ration, to reduce the risk of ruminal acidosis in cattle. Can J Anim Sci 2006, 86:429-437.

13. Mutsvangwa T, Walton JP, Plaizier JC, Duffield TF, Bagg R, Dick P, Vessie G, McBride BW: Effects of a monensin controlled-release capsule or premix on attenuation of subacute ruminal acidosis in dairy cows. J Dairy Sci 2002, 85:3454-3461.

14. Marounek $M$, Bartos $S$, Brezina P: Factors influencing the production of volatile fatty acids from hemicellulose, pectin and starch by mixed culture of rumen microorganisms. Zeitschrift für Tierphysiologie Tierernährung und Futtermittelkunde 1985, 53:50-58.

15. Krause KM, Oetzel GR: Inducing subacute ruminal acidosis in lactating dairy cows. J Dairy Sci 2005, 88:3633-3639.

16. Enjalbert F, Videau Y, Nicot MC, Troegeler-Meynadier A: Effects of induced subacute ruminal acidosis on milk fat content and milk fatty acid profile. J Anim Physiol An N 2008, 92:284-291.

17. Lammers BP, Buckmaster DR, Heinrichs AJ: A simple method for the analysis of particle sizes of forage and total mixed rations. J Dairy Sci 1996, 79:922-928.

18. AOAC: Official methods of analysis. 15th edition. Washington, DC: Association of Official Analytical Chemists; 1990.

19. Bal MA, Shaver RD, Jirovec AG, Shinners KJ, Coors JG: Crop processing and chop length of corn silage: effects on intake, digestion, and milk production by dairy cows. J Dairy Sci 2000, 83:1264-1273.

20. Van Soest PJ, Robertson JB, Lewis BA: Methods for dietary fiber, neutral detergent fiber, and nonstarch polysaccharides in relation to animal nutrition. J Dairy Sci 1991, 74:3583-3597.

21. Van Keulen J, Young BA: Evaluation of acid-insoluble ash as a natural marker in ruminant digestibility studies. J Anim SCi 1977, 44:282-287.

22. Zhong RZ, Li JG, Gao YX, Tan ZL, Ren GP: Effects of substitution of different levels of steam-flaked corn for finely ground corn on lactation and digestion in early lactation dairy cows. J Dairy Sci 2008, 91:3931-3937.

23. Yang R, Le G, Li A, Zheng J, Shi Y: Effect of antioxidant capacity on blood lipid metabolism and lipoprotein lipase activity of rats fed a high-fat diet. Nutrition 2006, 22:1185-1191.
24. Richard MJ, Portal B, Meo J, Coudray C, Hadjian A, Favier A: Malondialdehyde kit evaluated for determining plasma and lipoprotein fractions that react with thiobarbituric acid. Clin Chem 1992, 38:704-709.

25. Hafeman DG, Sunde RA, Hoekstra WG: Effect of dietary selenium on erythrocyte and liver glutathione peroxidase in the rat. J Nutr 1974, 104:580-587.

26. AlZahal O, Or-Rashid MM, Greenwood SL, McBride BW: Effect of subacute ruminal acidosis on milk fat concentration, yield and fatty acid profile of dairy cows receiving soybean oil. J Dairy Res 2010, 77:376-384.

27. Enemark J: The monitoring, prevention and treatment of sub-acute ruminal acidosis (SARA): a review. Vet J 2008, 176:32-43.

28. Khafipour E, Krause DO, Plaizier JC: A grain-based subacute ruminal acidosis challenge causes translocation of lipopolysaccharide and triggers inflammation. J Dairy Sci 2009, 92:1060-1070.

29. Cottee G, Kyriazakis I, Widowski TM, Lindinger MI, Cant JP, Duffield TF, Osborne VR, McBride BW: The effects of subacute ruminal acidosis on sodium bicarbonate-supplemented water intake for lactating dairy cows. J Dairy Sci 2004, 87:2248-2253.

30. Leddin CM, Stockdale CR, Hill J, Heard JW, Doyle PT: Increasing amounts of crushed wheat fed with pasture hay reduced dietary fiber digestibility in lactating dairy cows. J Dairy Sci 2009, 92:2747-2757.

31. Firkins JL: Effects of feeding nonforage fiber sources on site of fiber digestion. J Dairy Sci 1997, 80:1426-1437.

32. Stensig T, Weisbjerg MR, Hvelplund T: Digestion and passage kinetics of fibre in dairy cows as affected by the proportion of wheat starch or sucrose in the diet. Acta Agriculturae Scandinavica A-Animal Sciences 1998, 48:129-140.

33. Krajcarski-Hunt H, Plaizier JC, Walton JP, Spratt R, McBride BW: Short communication: effect of subacute ruminal acidosis on in situ fiber digestion in lactating dairy cows. J Dairy Sci 2002, 85:570-573.

34. Mojtahedi M, Danesh Mesgaran M: Effects of the inclusion of dried molassed sugar beet pulp in a low-forage diet on the digestive process and blood biochemical parameters of Holstein steers. Livest Sci 2011, 141:95-103

35. Herrera-Saldana RE, Huber JT, Poore MH: Dry matter, crude protein, and starch degradability of five cereal grains. J Dairy Sci 1990, 73:2386-2393.

36. Roche JR, Sheahan AJ, Chagas LM, Boston RC: Short communication: change in plasma ghrelin in dairy cows following an intravenous glucose challenge. J Dairy Sci 2008, 91:1005-1010.

37. Andersson L, Lundstroem K: Effect of feeding silage with high butyric acid content on ketone body formation and milk yield in postparturient dairy cows. Zentralblatt fuer Veterinaermedizin 1985, 32:15-23.

38. Heitmann RN, Fernandez JM: Autoregulation of alimentary and hepatic ketogenesis in sheep. J Dairy Sci 1986, 69:1270-1281.

39. Chiarla C, Giovannini I, Siegel JH: The relationship between plasma cholesterol, amino acids and acute phase proteins in sepsis. Amino Acids 2004, 27:97-100

40. Gozho GN, Krause DO, Plaizier JC: Rumen lipopolysaccharide and inflammation during grain adaptation and subacute ruminal acidosis in steers. J Dairy Sci 2006, 89:4404-4413.

41. Van Nevel CJ, Demeyer DI: Influence of $\mathrm{pH}$ on lipolysis and biohydrogenation of soybean oil by rumen contents in vitro. Reprod Nutr Dev 1996, 36:53-63.

42. Staples CR, Thatcher WW, Clark JH: Relationship between ovarian activity and energy status during the early postpartum period of high producing dairy cows. J Dairy Sci 1990, 73:938-947.

43. Van Knegsel A, Van den Brand H, Graat E, Dijkstra J, Jorritsma R, Decuypere E, Tamminga S, Kemp B: Dietary energy source in dairy cows in early lactation: metabolites and metabolic hormones. J Dairy Sci 2007, 90:1477-1485.

44. Reynolds CK: Production and metabolic effects of site of starch digestion in dairy cattle. Anim Feed Sci Tech 2006, 130:78-94.

45. Brockman RP: Role of insulin in regulating hepatic gluconeogenesis in sheep. Can J Physiol Pharm 1985, 63:1460-1464.

46. Sordillo LM: Factors affecting mammary gland immunity and mastitis susceptibility. Livest Prod Sci 2005, 98:89-99.

47. Halliwell $B$, Whiteman M: Measuring reactive species and oxidative damage in vivo and in cell culture: how should you do it and what do the results mean? Brit J Pharmacol 2009, 142:231-255.

48. Ghiselli A, Serafini M, Natella F, Scaccini C: Total antioxidant capacity as a tool to assess redox status: critical view and experimental data. Free Radical Bio Med 2000, 29:1106-1114. 
49. Hou Z, Wang Z, Chai T, Jia Y, Gong Q, Ma J, Wang Y: Effects of forage to concentrate ratio on homeostasis of rumen and oxidative stress in cows. Chinese Journal of Animal and Veterinary Sciences 2008, 39:455-459.

50. Gabai G, Testoni S, Piccinini R, Marinelli L, Stradaioli G: Oxidative stress in primiparous cows in relation to dietary starch and the progress of lactation. Anim Sci 2004, 79:99-108.

51. Ametaj BN, Zebeli Q, Saleem F, Psychogios N, Lewis MJ, Dunn SM, Xia JG, Wishart DS: Metabolomics reveals unhealthy alterations in rumen metabolism with increased proportion of cereal grain in the diet of dairy cows. Metabolomics 2010, 6:583-594.

52. Yu BP: Cellular defenses against damage from reactive oxygen species. Physiol Rev 1994, 74:139-162.

53. Collins AR: Assays for oxidative stress and antioxidant status: applications to research into the biological effectiveness of polyphenols. Am J Clin Nutr 2005, 81:261S-267S

54. Sharma N, Singh NK, Singh OP, Pandey V, Verma PK: Oxidative stress and antioxidant status during transition period in dairy cows. Asian Austral $J$ Anim 2011, 24:479-484.

doi:10.1186/2049-1891-4-31

Cite this article as: Guo et al:: Changes in feed intake, nutrient digestion,

plasma metabolites, and oxidative stress parameters in dairy cows with

subacute ruminal acidosis and its regulation with pelleted beet pulp.

Journal of Animal Science and Biotechnology 2013 4:31.

\section{Submit your next manuscript to BioMed Central and take full advantage of:}

- Convenient online submission

- Thorough peer review

- No space constraints or color figure charges

- Immediate publication on acceptance

- Inclusion in PubMed, CAS, Scopus and Google Scholar

- Research which is freely available for redistribution 